\title{
Effects of ion beam irradiation on the regeneration and morphology of Ficus thunbergii Maxim
}

\author{
Misa Takahashi ${ }^{1,2 *}$, Sueli Kohama ${ }^{1}$, Komei Kondo ${ }^{1}$, Makoto Hakata ${ }^{1}$, Yoshihiro Hase ${ }^{3}$, \\ Naoya Shikazono ${ }^{3}$, Atsushi Tanaka ${ }^{3}$, Hiromichi Morikawa ${ }^{1,2}$ \\ ${ }^{1}$ Department of Mathematical and Life Sciences, Graduate School of Science, Hiroshima University, \\ 1-3-1, Kagamiyama, Higashi-Hiroshima, Hiroshima 739-8526, Japan \\ ${ }^{2}$ Core Research for Evolutional Science and Technology (CREST), Japan Science and Technology Agency (JST), \\ 4-1-8, Honcho, Kawaguchi, Saitama 332-0012, Japan \\ ${ }^{3}$ Department of Ion-Beam-Applied Biology, Takasaki Radiation Chemistry Research Establishment, Japan Atomic \\ Energy Research Institute, 1233 Watanuki-machi, Takasaki, Gunma 370-1292, Japan \\ *E-mail: mtakahas@sci.hiroshima-u.ac.jp Tel: +81-82-424-7494 Fax: +81-82-424-0749
}

Received October 13, 2004; accepted November 26, 2004 (Edited by T. Kohchi)

\begin{abstract}
Shoot explants cut from aseptically grown Ficus thunbergii plants were irradiated with ${ }^{12} \mathrm{C}^{5+},{ }^{12} \mathrm{C}^{6+}$ and ${ }^{4} \mathrm{He}^{2+}$ ion beams of 10 to 200 Gray (Gy). After irradiation, the explants were allowed to regenerate. The regeneration frequency $(\mathrm{RF})$, or percent explants bearing regenerated shoots to the total number of explants irradiated, decreased in a dosedependent manner. Morphological changes in leaves and stems were observed in regenerants. The morphological change frequency (MF), or percent regenerants bearing morphologically changed shoots to the total number of regenerants peaked at 15 to $25 \%$ at the dose of each ion beam that gave an RF of about $80 \%$ (except for ${ }^{4} \mathrm{He}^{2+}$ ). A negative correlation was observed between the linear energy transfer (LET) and ion beam dose both in RF and MF. The present results strongly suggest that ion beam irradiation can induce mutations in the genome of $F$. thunbergii.
\end{abstract}

Key words: Creeping fig, Ficus thunbergii, ion beam irradiation, variegation.

Induced mutation is an important tool for producing genetic variations (Brunner 1995). Ion beams possess advantages for this purpose since they have a linear energy transfer (LET) much higher than that of X-rays or $\gamma$-rays (Tanaka et al. 1997a; Hase et al. 1999). In addition, the deposition of high energy on a focal target exposed to irradiation is controllable with ion beams (Tanaka et al. 1997a, c; Hase et al. 1999).

Ion beam irradiation reportedly causes double-strand breaks (Shikazono et al. 1998) and chromosome aberrations (Wu and $\mathrm{Yu}$ 2001), and is known to induce various mutations including the formation of periclinal or sectorial variegated chimeras in tobacco plants (Brunner 1995; Bae et al. 2000), decreased germination rates in Arabidopsis (Tanaka et al. 1997a) and Nicotiana tabacum (Hase et al. 1999), spotted pigmentation in Arabidopsis (Tanaka et al. 1997b), and albinism in $N$. tabacum (Bae et al. 2001). More recently, an ultravioletB-resistant mutant of Arabidopsis was obtained by ion beam irradiation (Tanaka et al. 2002).

Ficus thunbergii or creeping fig, which belongs to the Moraceae or mulberry family, is an evergreen climber that has been used to cover the walls of houses and buildings (Takahashi et al. 2002). Plants can be used to decontaminate pollutants such as nitrogen dioxide emanated both naturally and artificially into the atmosphere. We previously reported that the capability of plants to assimilate atmospheric nitrogen dioxide varied more than 600 -fold among more than 200 plant species, indicating the importance of screening plants in phytoremediation (Morikawa et al. 1998; Takahashi et al. 2003). The eventual aim of this study is to obtain mutant F. thunbergii plants induced by ion beam irradiation that have a high capability to take up and assimilate atmospheric nitrogen dioxide.

Aseptically grown $F$. thunbergii plants were cultured in plastic containers (Agripot, Kirin, Japan) containing Florialite (Nisshinbo, Japan) with Murashige and Skoog

Abbreviations: Japan Atomic Energy Research Institute (JAERI); Gray (Gy); linear energy transfer (LET); Murashige and Skoog medium (MS medium); indole-3-butyric acid (IBA); woody plant medium (WPM); benzyl adenine (BA); thidiazuron (TDZ); regeneration frequency (RF); morphological change frequency (MF)

Misa Takahashi, Department of Mathematical and Life Sciences, Graduate School of Science, Hiroshima University, Hiroshima 739-8526, Japan 
medium (MS medium; Murashige and Skoog 1962) supplemented with $2 \%$ sucrose and $1 \mathrm{mg} \mathrm{ml}^{-1}$ indole-3butyric acid (IBA). The plants were cultured for up to two months in a culture room (Model TCR-5P, Nippon Medical \& Chemical Instruments Co., Japan), at $25 \pm 1^{\circ} \mathrm{C}$ in the light (30 to $40 \mu \mathrm{mol}$ photons $\mathrm{s}^{-1} \mathrm{~m}^{-2}$ ). When shoots grew to about $60-\mathrm{mm}$ long, a $50-\mathrm{mm}$ long apical section, containing the apex and three subsequent nodes was excised. Each section was cut into two parts: a 4-mm long top (apex) section and three 2-mm long node sections. The top section was cut longitudinally down the middle while the node sections were not. About 20 explants were placed in a $60-\mathrm{mm}$ Petri dish with shoot formation medium consisting of woody plant medium (WPM; Lloyd and McCown 1980) supplemented with $2 \%$ sucrose, $0.3 \%$ Gellan Gum, $1.78 \mu \mathrm{M}$ benzyl adenine (BA) and $46.7 \mathrm{nM}$ thidiazuron (TDZ), pH 5.8. Each Petri dish was covered with a thin kapton film (Toray-Dupon Co., Japan), and the explants were cultured at $25 \pm 1^{\circ} \mathrm{C}$ in the light ( 30 to $40 \mu \mathrm{mol}$ photons $\mathrm{s}^{-1} \mathrm{~m}^{-2}$ ).

The following day, the explants were irradiated with ${ }^{12} \mathrm{C}^{5+}(220 \mathrm{MeV}),{ }^{12} \mathrm{C}^{6+}(320 \mathrm{MeV})$ or ${ }^{4} \mathrm{He}^{2+}(50 \mathrm{MeV})$ ion beams, with an irradiation dose ranging from 10 to 200 Gray (Gy), using the azimuthally varying field (AVF) cyclotron at the Japan Atomic Energy Research Institute (JAERI), Takasaki, Japan. The physical properties of the ion beams used in this study are summarized in Table 1. After irradiation, the explants were transferred to fresh shoot formation medium and cultured for up to 3 months by subculturing of every 3 weeks. When the buds became $20 \mathrm{~mm}$ long, they were cut, transferred to test tubes $3 \mathrm{~cm}$ in diameter and $20 \mathrm{~cm}$ long containing florialite with MS medium supplemented with $2 \%$ sucrose and IBA.

The frequency of shoots regeneration from the irradiated explants (hereafter designated RF) was determined using the following equation after three months of culture:

\section{$\mathrm{RF}=($ the number of explants bearing regenerated shoots/total number of irradiated explants $) \times 100$ $(\%)$.}

This parameter was considered a measure of the effectiveness of each ion beam $\left({ }^{12} \mathrm{C}^{5+},{ }^{12} \mathrm{C}^{6+}\right.$ and $\left.{ }^{4} \mathrm{He}^{2+}\right)$ employed here; results are shown in Figure 1. In general, $\mathrm{RF}$ values decreased in a dose-dependent manner for ${ }^{12} \mathrm{C}^{5+}$ (Figure 1A), ${ }^{12} \mathrm{C}^{6+}$ (Figure 1B) and ${ }^{4} \mathrm{He}^{2+}$ (Figure $1 \mathrm{C})$. It should be noted that the dose of ion beams required to give the same RF value differed among beams; to attain an RF value of $80 \%$, doses of 10,23 and $50 \mathrm{~Gy}$ were needed for ${ }^{12} \mathrm{C}^{5+},{ }^{12} \mathrm{C}^{6+}$ and ${ }^{4} \mathrm{He}^{2+}$ respectively. This indicates that the higher the LET, which reflects the capability to transfer beam energy to the target cells, of the ion beam the lower the dose
Table 1. Physical properties of the ion beams used in this study.

\begin{tabular}{cccc}
\hline Ion & $\begin{array}{c}\text { Total energy } \\
(\mathrm{MeV})\end{array}$ & $\begin{array}{c}\text { Mean LET } \\
\left(\mathrm{keV} \mu \mathrm{m}^{-1}\right)\end{array}$ & $\begin{array}{c}\text { Penetration } \\
\text { depth }(\mathrm{mm})\end{array}$ \\
\hline${ }^{12} \mathrm{C}^{5+}$ & 220 & 159 & 1.1 \\
${ }^{12} \mathrm{C}^{6+}$ & 320 & 86 & 2.3 \\
${ }^{4} \mathrm{He}^{2+}$ & 50 & 19 & 1.7 \\
\hline
\end{tabular}

${ }^{\text {a }}$ Linear energy transfer (LET).

${ }^{\mathrm{b}}$ Calculated as water equivalent.
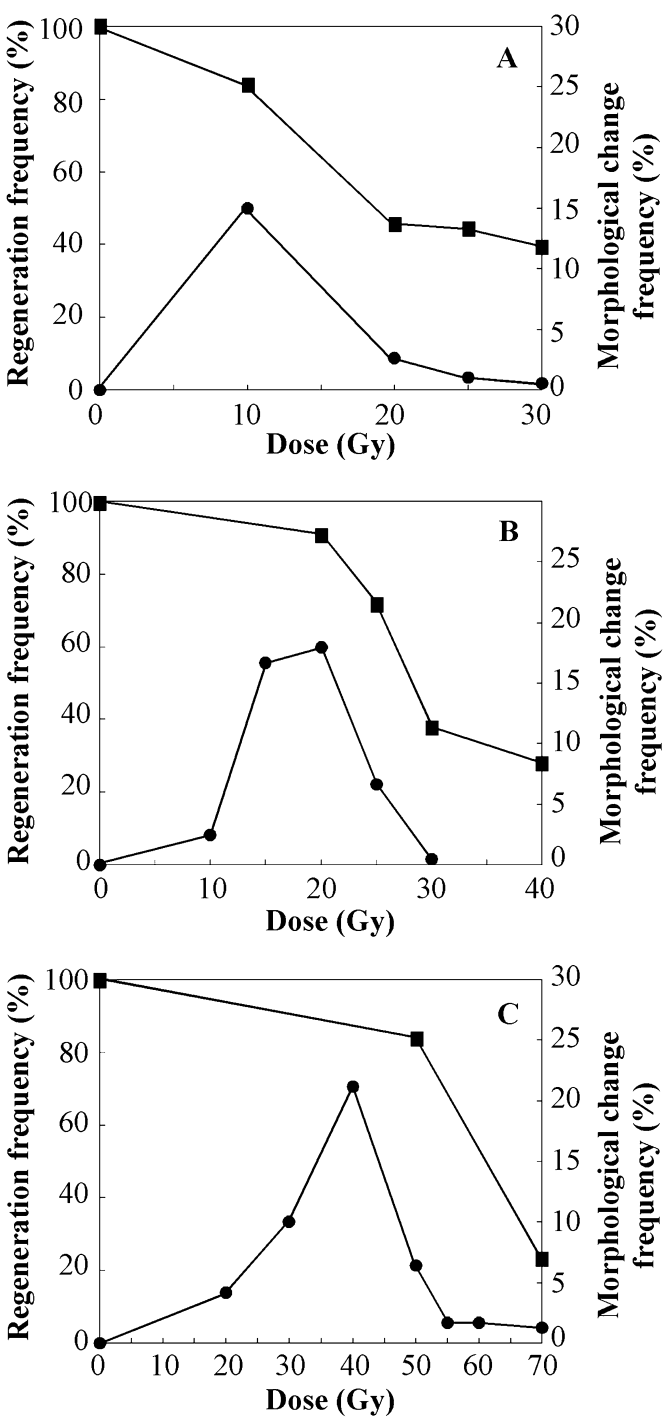

Figure 1. Effects of the irradiation dose of ${ }^{12} \mathrm{C}^{5+}$ (panel A), ${ }^{12} \mathrm{C}^{6+}$ (panel B) and ${ }^{4} \mathrm{He}^{2+}$ (panel C) ion beams on the regeneration (square) and morphological change frequencies in $F$. thunbergii regenerants (circle). See text for details

required to attain the same level of RF (see Figure 1 and Table 1).

Beyond these doses, ion beam irradiation caused further decreases in the RF; RF decreased to $40 \%$ when a dose of 30-, 30- and 60-Gy of ${ }^{12} \mathrm{C}^{5+},{ }^{12} \mathrm{C}^{6+}$ and ${ }^{4} \mathrm{He}^{2+}$, respectively, were given. This suggests that each of these ion beams affects the nuclei of the target cells. 

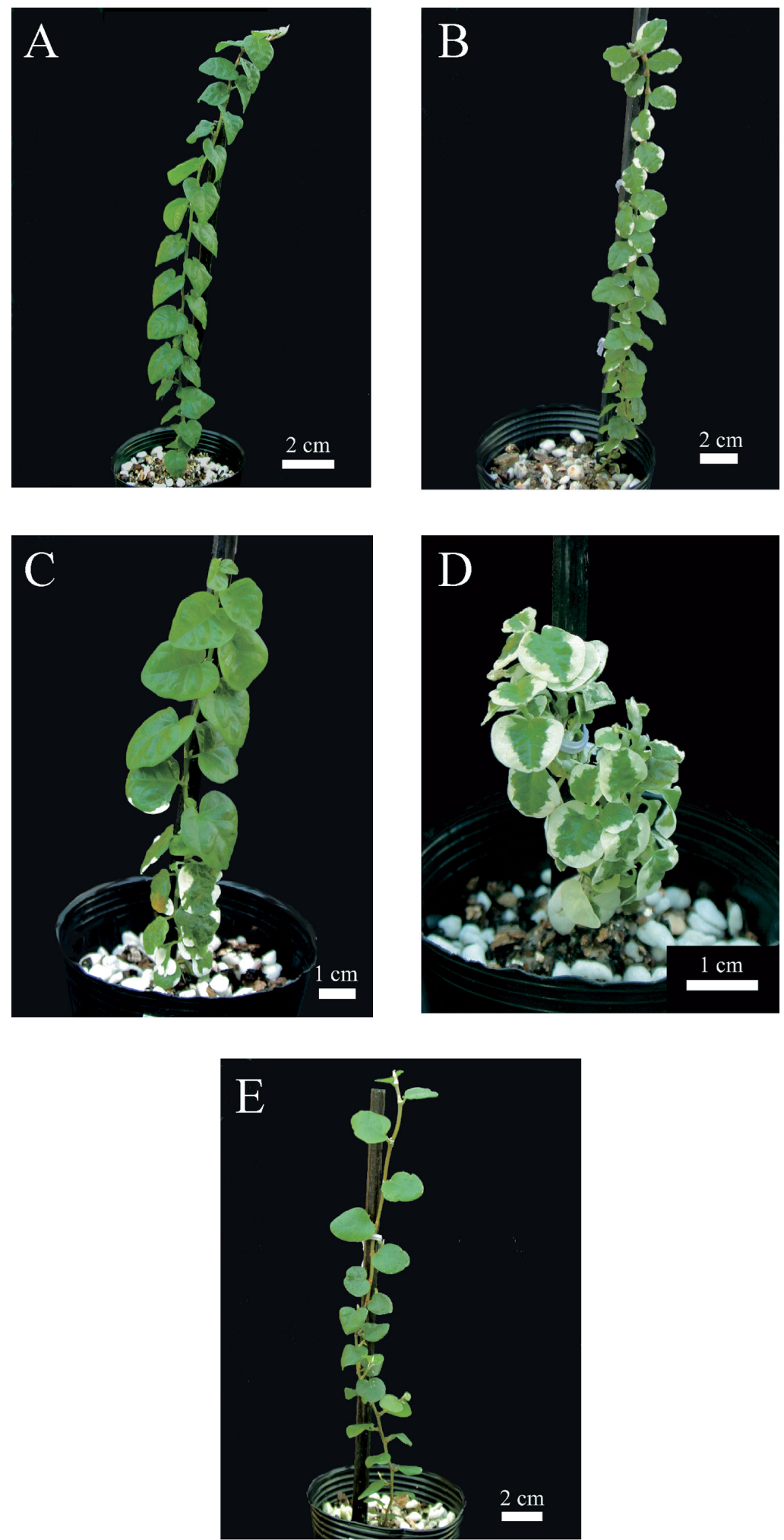

Figure 2. Photographs of typical regenerants of $F$. thunbergii showing morphological changes after ion beam irradiation. (A) Non-irradiated wildtype F. thunbergii, (B) a regenerant after irradiation with ${ }^{12} \mathrm{C}^{6+}$ at $20 \mathrm{~Gy}$ bearing white patches in almost all leaves, (C) a regenerant after irradiation with ${ }^{12} \mathrm{C}^{6+}$ at $20 \mathrm{~Gy}$ bearing white patches in lower (older) leaves, (D) a regenerant after irradiation with ${ }^{12} \mathrm{C}^{6+}$ at 20 Gy bearing large white patches in all leaves, and (E) a regenerant after irradiation with ${ }^{4} \mathrm{He}^{2+}$ at $50 \mathrm{~Gy}$ bearing a stem with reduced nodes in which the length of the internodes is distinctly greater than that of the respective organs in the wild-type (compare $\mathrm{E}$ with $\mathrm{A}$ ). 
Some of the regenerants exhibited morphological changes (mostly) in leaves and (rarely) in stems (see below). The frequency of these morphological changes (designated MF) was determined using the following equation and depicted in Figure 1 (lower curve in each of the panels).

\section{$\mathrm{MF}=$ (number of morphologically-changed regenerants/total number of regenerants $) \times 100$ $(\%)$.}

This value serves as another measure of the effectiveness of ion beams on the $F$. thunbergii genome. The MF value peaked at about 15 to $25 \%$ with 10,20 and $40 \mathrm{~Gy}$, respectively, for the ${ }^{12} \mathrm{C}^{5+},{ }^{12} \mathrm{C}^{6+}$ and ${ }^{4} \mathrm{He}^{2+}$ ion beams. For each condition, 100 to 200 regenerants were examined. More than $90 \%$ of the morphological changes were observed in the leaves, while the remaining was in the stems. It is noteworthy that the dose of each ion beams is very close (except for ${ }^{4} \mathrm{He}^{2+}$ ) to the dose that gave an RF of about $80 \%$ (see Figure 1). Clearly, there was a negative correlation between the dose that gives the peak MF and LET values as in the case of the correlation between RF and LET described above.

Figure 2 shows photographs of the typical regenerants of $F$. thunbergii bearing morphological changes in leaves and internodes. Some of the regenerants had variegated leaves with white patches (Figures 2B, C and D), the size of the white patches varied from small (Figures $2 \mathrm{~B}$ and C) to large (Figure 2D). In some cases, white patches appeared in an age-dependent manner, as depicted in Figure 2C, younger leaves or those in the upper part of the plant body show no variegation, but variegation appeared in the lower or aged leaves; the reason for this is unclear. It should be noted, however, that in the present regenerants the white patch was always observed in the peripheral border of the leaves (see Figure 2). Conceivably, morphological changes that induced the observed variegation might have occurred in the L1 and L2 layers (Bae et al. 2000). In general, the regenerants bearing variegated leaves exhibited a slow growth rate.

Some other regenerants obtained in the present study had longer internodes in which the number of nodes was distinctly smaller than that of the wild-type (Figure 2E). The leaves of these morphologically changed regenerants were smaller in size than the wild-type, and their shape was more or less deformed.

Various mutants with variegated leaves have been reported by previous authors. For example, Bae et al. (2000) reported periclinal white and green chimeric tobacco plants regenerated from explants irradiated with nitrogen ion beams. Furthermore, Aluru et al. (2001) reported that the Arabidopsis mutant in which a nuclear gene IMMUTANS was defected, bears white and green variegated leaves and slow growth. Cybrids of tomato with variegated sectoring light and dark green patches in the leaves, stem and fruits reportedly showed slow growth (Bonemma et al. 1995). There are two possible explanations for the origin of the variegated plants obtained in this study: (i) ion beam affected a cell or cells of the L1 or L2 layer of the apical meristem in the explant, and (ii) ion beams affected the embryogenic cell from which the regenerant developed. In the former case, the regenerants genetically differ in different parts of the plant body, and thus the regenerants are chimeras. In the latter case, the regenerants are not chimeric but are genetically homogeneous throughout the plant body. The latter is more likely because when green nodes without variegation taken from variegated plants were cultured in vitro, the regenerants obtained showed a similar variegation in all leaves (data not shown).

Molecular genetic mechanism for the induction of variegation of the leaves has been discussed in relation to the formation of defected chloroplasts or mitochondria by mutations of the nuclear or organellar genes (Bonemma et al. 1995; Aluru et al. 2001; Sakamoto 2003). Genes involved in the observed morphological changes in $F$. thunbergii are to be studied in future. In conclusion, our present finding indicates that ion beam irradiation can be used as a tool to induce mutations in $F$. thunbergii. Current work is being conducted to evaluate the capacity of regenerant irradiated $F$. thunbergii plants to mitigate atmospheric air pollutants.

\section{Acknowledgements}

This work was supported in part by a grant in aid for Scientific Research from the Ministry of Education, Science, Sports and Culture of Japan.

\section{References}

Aluru MR, Bae H, Wu D, Rodermel SR (2001) The Arabidopsis immutans mutation affects plastid differentiation and the morphogenesis of white and green sectors in variegated plants. Plant Physiol 127: 67-77

Bae CH, Abe T, Matsuyama T, Fukunishi N, Nagata N, Nakano T, Kaneko Y, Miyoshi K, Matsushima H, Yoshida S (2001) Regulation of chloroplast gene expression is affected in alli, a novel tobacco albino mutant. Annal Bot 88: 545-553

Bae C, Abe T, Nagata N, Fukunishi N, Matuyama T, Nakano T, Yoshida S (2000) Characterization of a periclinal chimera variegated tobacco (Nicotiana tabacun L.). Plant Sci 151: 93101

Bonnema AB, Castillo C, Reiter N, Cunningham M, Adams HP, O'Connell M (1995) Molecular and Ultrastructural Analysis of a Nonchromosomal Variegated Mutant. Tomato Mitochondrial Mutants That Cause Abnormal Leaf Development. Plant Physiol 109: 385-392

Brunner H (1995) Radiation induced mutations for plant selection. Appl Radiat Isol 46: 589-594 
Hase Y, Shimono K, Inoue M, Tanaka A, Watanabe H (1999) Biological effects of ion beams in Nicotiana tabacum $\mathrm{L}$. Radiat Environ Biophys 38: 111-115

Lloyd G, McCown B (1980) Commercially-feasible micropropagation of mountain laurel, Kalmia latifolia, by use of shoot tip culture. Intern Plant Prop Soc Proc 30: 421-427

Morikawa H, Higaki A, Nohno M, Takahashi M, Kamada M, Nakata M, Toyohara G, Okamura Y, Matsui K, Kitani S, Fujita K, Irifune K, Goshima N (1998) More than 600-fold variation in nitrogen dioxide assimilation among 217 plant taxa. Plant Cell Environ 21: 180-190

Murashige T, Skoog F (1962) A revised medium for a rapid growth and bioassay with tobacco tissue culture. Physiol Plant 15: 473-489

Sakamoto W (2003) Leaf-variegated mutations and their responsible genes in Arabidopsis thaliana. Genes Genet Syst 78: $1-9$

Shikazono N, Yokota Y, Tanaka A, Watanabe H, Tano S (1998) Molecular analyses of carbon-induced mutations in Arabdopsis thaliana. Genes Genet Syst 73: 173-179

Takahashi M, Kohama S, Kondo K, Hakata M, Hase Y, Shikazono N, Tanaka A, Morikawa H (2002) Ion beam-induced variegation in Ficcus stipulata Thunb. Ann Rep TIARA 39: 62-63

Takahashi M, Kondo K, Morikawa H (2003) Assimilation of nitrogen dioxide in selected plant taxa. Acta Biotechnol 23: 241-247

Tanaka A, Shikazono N, Yokota Y, Watanabe H, Tana S, (1997a) Effects of heavy ions on the generation and survival of Arabidopsis thaliana. Int J Rad Biol 1: 121-127

Tanaka A, Tano S, Chantes T, Yokota Y, Shikazono N, Watanabe H (1997b) A new Arabidopsis mutant induced by ion beams affects flavonoid synthesis with spotted pigmentation in testa. Genes Genet Syst 72: 141-148

Tanaka A, Watanabe H, Shimizu T, Inoue M, Kikuchi M, Kobayashi Y, Tano S (1997c) Penetration controlled irradiation with ion beams for biological study. Nucl Instr and Meth in Phys Res B 129: 42-48

Tanaka A, Sakamoto A, Ishigaki Y, Nikaido O, Sun G, Hase H, Shikazono N, Tano S, Watanabe H (2002) An ultraviolet-Bresistant mutant with enhanced DNA repair in Arabidopsis. Plant Physiol 129: 64-71

Wu L, Yu Z (2001) Radiobiological effects of a low-energy ion beam on wheat. Radiat Environ Biophys 40: 53-57 